\title{
Relationship between Sociodemographic Characteristics, Psychiatric Burden and Violent Offence in a Maximum Security Prison in North-Central Nigeria
} Armiya'u $\mathrm{AY}^{* 1}$ and Adole $\mathrm{O}^{2}$

${ }^{1}$ Consultant forensic psychiatrist, Department of psychiatry, Jos University Teaching Hospital, Jos. Plateau state, Nigeria

${ }^{2}$ Consultant psychiatrist and head of department of psychiatry and psychosocial services, 44 Nigerian Army

Reference Hospital Kaduna, Kaduna state Nigeria

${ }^{*}$ Corresponding author: Armiya'u AY, Consultant forensic psychiatrist, Department of psychiatry, Jos University Teaching Hospital, Jos. Plateau state, Nigeria, Tel: +2348035899338, E-mail: aarmiyau@gmail. com

Citation: Armiya'u AY, Adole O (2015) Relationship between Sociodemographic Characteristics, Psychiatric Burden and Violent Offence in a Maximum Security Prison in North-Central Nigeria. J Forensic Sci Criminol 3(2): 202 . doi: 10.15744/2348-9804.2.502

Received Date: February 21, 2015 Accepted Date: April 28, 2015 Published Date: April 30, 2015

\begin{abstract}
Background: Violent offenders are individuals who are incarcerated due to any criminal charge for a violent offence against another individual-armed robbery, murder, attempted murder, kidnapping, assault which results in bodily harm and forcible confinement. Efforts should be made to distinguish violent from non-violent individuals in the prison for better and appropriate provision of treatment settings for each due to the potential risk of the violent offenders, much to the detriment of non-violent inmates who are usually predominant in prison.
\end{abstract}

Aim: The study was carried out to evaluate the Sociodemographic correlates of violent offenders and to determine their psychiatric morbidity and its relationship to violent offence.

Method: A cross-sectional descriptive study was carried out among 329 violent offenders (armed robbers and murderers) both awaiting trial and convicted inmates. They were administered a questionnaire consisting of Sociodemographic and forensic variables, screened with self-administered GHQ-28 questionnaire and interviewed with the CIDI.

Results: More than half (60\%) of the studied sample had a psychiatric disorder with substance use disorder the commonest (26.1\%) diagnosis. A significant relationship was found between psychiatric disorder and category of violent offenders $(\mathrm{p}=0.000)$, with substance use disorder more prevalent among violent offenders awaiting trial 68 (38.2\%), so also a significant association was found between age and psychiatric disorder $(\mathrm{p}=0.040)$.

Conclusion: A high rate of psychiatric disorder was found among violent offenders, with substance use disorder the commonest diagnosis among the youths (15-34years).

Keywords: Violent offenders; Convicted; Awaiting trial; Maximum security prison; Psychiatric disorder

\section{Introduction}

Violence refers to an act of physical aggression against others. It is reported as the sixth leading cause of death among the age group 15-44 and in the United States the fifth leading cause of death among the age group 10-60 [1,2]. Survivors of violent act, suffer physical injuries and psychological consequences, making it the twenty leading cause of disability [3].

Intentional or purposeful use of power or physical force against self, others or against community or group in an actual or threatened manner which could eventually result to psychological harm, injury, deprivation, death or maldevelopment refers to violence [1]. Violence globally results in the death of over 1.6million people annually with suicide, homicide and death resulting from war/ conflict accounting for $50 \%, 35 \%$ and $12 \%$ respectively [1].

Violence occurs at all levels of social life, and in virtually every aspect of human-life as such it is a core part of human-nature. As part of human existence violence includes racial/religious violence, violence between the strong and weak, either communally or individually, violence within household, violence as an act of crime, violence between communities and finally perpetration of violence on mankind itself. Violence is a social-construct [4] to an extent of being ingrained into the whole of human-evolution.

Violence when viewed in the context of mental illness can be sensationalized, and this leads to more stigmas which have already been permeated in the lives of mentally ill individuals [5].

Violence in a person with psychiatric illness is not necessarily a consequence of that illness and, conversely, all violence is not necessarily a consequence of mental illness, [6]. Psychiatrist, therefore, should be more concern on the aetiology of violence in the 
individual so that they may attend to that which is within their province. According to Mackintosh (1990) [7] aetiology of violence is complex which is further confounded by the terminology. The issue of violence and crime among mentally disordered persons has been an important subject for both clinical and policy makers.

For several decades it was believed that mentally ill individuals were no more likely to be violent than the non-mentally ill individuals. Studies have found modest relationship between mental disorders and violence and it is generally agreed that mentally ill individuals are more prone to violence than general population [8-12].

Violence and mental illness are usually linked together, which results in harsh stigma for the mentally ill individual, sometimes the environment becomes uncomfortable even for the mental health professionals [5]. This perception carries a lot of consequences for these individuals which further discriminates and isolate them from the society [13]. The likelihood to commit violence is increased in some persons with mental illness. This is evident in the vast evidence that links substance use disorder with incidence of violent crimes [14].

According to Holcomb \& Ahr (1988) [14], more individuals with drug and alcohol problems were arrested over their life time, when compared to other mental health problems. Problems of alcohol in combination with antisocial personality disorder has a 40-50 fold increase for homicide crimes, while a 5-6 fold increase was found for schizophrenic persons [15]. Aggression was found to be $73 \%$ more likely in individuals with dual diagnosis of mental illness and substance use than those who do not abuse substances. In the same vein there was a $240 \%$ increase in violent crimes among individuals with substance use disorder and personality disorder than those who are mentally ill but not using substances [16].

There is a 16 fold increase in violent crime among schizophrenic individuals abusing substances, based on a study, which found violent crime conviction in $30 \%$ of male subjects' abusing substances with schizophrenic illness, [17].

Studies done in Sweden among homicide offenders found substance use disorder in 47\%, personality disorder in 54\%, while 25\% had schizophrenia, bipolar and other types of psychosis [18]. Swanson et al (1990) reported major mental disorders correlated with at least five fold increases in rate of violence over a one year period, when compared with rates among individuals without mental illness, and a tenfold increase in violence with people abusing substances. A study conducted in Turkey among convicted homicide and attempted homicide offenders found psychiatric morbidity in $51.4 \%$ with substance use disorder as the commonest in $45.7 \%$ of offenders [19]. In Nigeria a study on homicide offender's revealed psychiatric illness in $43.2 \%$ with offence found more among young male adults, from low social economic status [20]. Another retrospective study by [21] Mafullul (2001) among homicide offenders in Jos, Nigeria reported psychosis in 24\% of the 118 studied sample. A study in Jos by Armiya'u et al (2014) [22] found substance use disorder as the commonest psychiatric disorder among subjects studied. The same study found a significant association between substance use disorder and younger age group, but did not find a direct association with type of offence committed by the subjects.

\section{Method}

This study was a cross-sectional descriptive study conducted in two stages among 329 male violent offenders (murders and armed robbers) both convicted and awaiting trial in Jos maximum security prison, Plateau state.

Inclusion criteria include subjects must be willing to participate in the study and sign or thumb print the consent form provided before the commencement of the research. Exclusion criteria were refusal to sign or thumb prints the consent form and subjects that where severely ill at the time of the study.

The prison authorities facilitated a familiarization tour during which the researcher sought for cooperation of participants, at the prison conference hall, parade ground and in the clinic. It was emphasized to the participants that the researcher is neither a Prison Official nor a member of a Law Enforcement Agency, but a mental health professional. They were assured confidentiality of their responses.

The study was done in two stages; the first stage involved the administration of proforma questionnaires to retrieve Sociodemographic variables of the participants alongside the General Health Questionnaire-28 (GHQ-28) to all the 329 offenders.

The GHQ-28 is a self-administered screening instrument which was given to all of them. It was designed to cover four identifiable areas of distress: depression, anxiety, social impairment and hypochondriasis. Although it was not intended to detect severe illness such as schizophrenia or psychotic depression however, repeated experience with the GHQ scale has shown that it can be used to screen for the presence of these disorders in people [23]. It is used as a screening instrument for mental disorders following which the diagnosis is confirmed with a more specific instrument. The GHQ can be used in a large survey like an institutionalized population, primary health care center or community [24]. The original version contains 60 item questions, which was designed by Goldberg in 1972 [25], but shorter versions such as thirty (30), twenty eight (28), and twelve (12) were developed later. However, the GHQ-28 was used in this study. It consists of four sub scales measuring somatic symptoms, anxiety and insomnia, social dysfunction, and severe depression. Items on the GHQ may be scored using 0-1-2-3 Likert scale or 2 point score rate in which the problems are either present or absent. The Likert scale was used in this study. 
The GHQ questionnaires have been used in over 38 countries including Nigeria and over 50 validity studies have been published. It has been demonstrated to have high sensitivity and specificity [26,27].

In the second stage, offenders with a GHQ-28 score of 4 [28] and above where interviewed using the Composite International Diagnostic Interview (CIDI) which took the form of a clinical interview by the author who is trained in CIDI administration.

The CIDI was administered to all those with GHQ score of four and above. CIDI is a comprehensive, fully standardized interview that can be used to assess mental disorder and provide diagnosis according to the definition and criteria of the tenth revision of the International Classification of Diseases ICD 10 [29] and the fourth edition of the Diagnostic and Statistical Manual of mental disorder (DSM IV) (American Psychiatric Association, 1994). It was also proposed by the WHO, National Institute of Mental Health (NIMH), National Institute of Alcohol abuse/Alcoholism (NIAAA) and National Institute of Drug Abuse (NIDA) under National Institute of Health (NIH). The project was known as WHO/NIH joint project on diagnosis and classification of mental disorders, alcohol and drug related problems. The CIDI was designed for use in variety of cultures. The format of the interview will be to elicit life time or 12 month period of the presence of a symptom and using a number of probes to establish whether the symptom is of psychiatric importance. CIDI was written for persons with markedly different educational and cultural background and intelligence. The instrument has been validated, and used by researchers in different countries, e.g. in Nigeria by [22,30,31].

Data was analyzed using the statistical package of social sciences (SPSS) version 20.0. Student t-test was used for continuous variables and Chi-square for categorical variables. A probability of $5 \%$ was regarded as statistically significant. The sample used for the research was normally distributed. The sample was perfectly symmetrical (had a skew of 0 ), and had no kurtosis.

\section{Results}

\section{Sociodemographic characteristics of the participants}

The studied participants were all male (178 awaiting trial and 151 convicted) within an age range of 18 and $70 y e a r s$ with mean age of $32.1 \pm 10.6$ years. More than half 210 (63.8\%) of the participants were young offenders aged between 15-34 years, with 9 $(2.7 \%)$ aged 65 years and above (Table 1$)$. Half of the participants $165(50.2 \%)$ were single at the time of incarceration, $116(35.3 \%)$ were married, 33 (10.0\%) separated, while $15(4.6 \%)$ were widowers. One hundred and twenty six (38.3) of the participants were unemployed at the time of offence, 100 (30.4\%) employed, 66 (20.1\%) were students, with 37 (11.2\%) of the participants doing apprenticeship at the time of offence (Table 1).

\begin{tabular}{|c|c|c|c|c|c|}
\hline \multirow{2}{*}{ Variables } & \multicolumn{5}{|c|}{ N = 329 } \\
\cline { 2 - 6 } & ATM & Convict & Total & Percentage & Mean + Std \\
\hline Age in years & & & & & \\
\hline $15-24$ & 42 & 10 & 52 & 15.8 & \\
\hline $25-34$ & 97 & 61 & 158 & 48.0 & \\
\hline $35-44$ & 32 & 49 & 81 & 24.6 & $32.1 \pm 10.6$ \\
\hline $45-54$ & 3 & 15 & 18 & 5.5 & \\
\hline $55-64$ & 2 & 9 & 11 & 3.3 & \\
\hline$>65$ & 2 & 7 & 9 & 2.7 & \\
\hline Marital status & & & & & \\
\hline Married & 64 & 52 & 116 & 35.3 & \\
\hline Separated & 13 & 20 & 33 & 10.0 & \\
\hline Widowed & 7 & 8 & 15 & 4.6 & \\
\hline Single & 94 & 71 & 165 & 50.2 & \\
\hline Educational Status & & & & & \\
\hline Non formal & 26 & 42 & 68 & 20.7 & \\
\hline Primary & 34 & 30 & 64 & 19.5 & \\
\hline Secondary & 94 & 58 & 152 & 46.2 & \\
\hline Tertiary & 24 & 21 & 45 & 13.7 & \\
\hline Employment status & & & & & \\
\hline Unemployed & 92 & 34 & 126 & 38.3 & \\
\hline Employed & 30 & 70 & 100 & 30.4 & \\
\hline Student & 33 & 33 & 66 & 20.1 & \\
\hline Others & 23 & 14 & 37 & 11.2 & \\
\hline
\end{tabular}

Key: ATM = Awaiting trial

Psychiatric morbidity in the participants

Table 1: Sociodemographic characteristics of participants

Annex Publishers | www.annexpublishers.com 
The prevalence of psychiatric morbidity was high among violent offenders with more than half 200 (60.8\%) of the participants having psychiatric morbidity. The commonest diagnosis was Substance use disorder found in 86 (26.1\%), closely followed by depression in $70(21.3 \%)$ of the participants (Table 3). Results revealed that depression, generalized anxiety disorder (GAD) and panic disorder were more common among convicted violent offenders, while substance use disorder was more prevalent 68 (38.2\%) among the awaiting trial participants (Table 4).

\begin{tabular}{|c|c|c|}
\hline GHQ & Frequency & Percentage \\
\hline Cases & 200 & 60.8 \\
\hline No cases & 129 & 39.2 \\
\hline Total & $\mathbf{3 2 9}$ & $\mathbf{1 0 0}$ \\
\hline
\end{tabular}

Table 2: Psychiatric morbidity of participants by GHQ-28

Table 2 above showed the GHQ-28 score of the participants. This implies those with psychiatric disorders and those without using the cutoff point of 4 , it screened those with probable psychiatric disorder. This is before the administration of the diagnostic questionnaire CIDI which gave the precise psychiatric diagnosis of the participants.

\begin{tabular}{|c|c|c|c|c|}
\hline \multicolumn{5}{|c|}{ N = 329 } \\
\hline Type & ATM & Convicts & Total & Percentage \\
\hline Depression (D)Generalized Anxiety & 20 & 50 & 70 & 21.3 \\
\hline Disorder (G) & 10 & 17 & 27 & 8.2 \\
\hline Panic Disorder (P) & 5 & 12 & 17 & 5.2 \\
\hline Substance use Disorder (SU) & 68 & 18 & 86 & 26.1 \\
\hline No psychiatric Disorder & 75 & 54 & 129 & 39.2 \\
\hline
\end{tabular}

Table 3: Psychiatric morbidity of participants by CIDI

\section{Association between psychiatric morbidity and violent offence}

A significant relationship was found between psychiatric disorder and category of violent offenders $(p=0.000)($ Table 4$)$

\begin{tabular}{|c|c|c|c|}
\hline \multicolumn{4}{|c|}{ N=329 } \\
\hline Type & ATM & Convicts & Total \\
\hline Depression (D)Generalized Anxiety & $20(11.2 \%)$ & $50(33.1 \%)$ & $70(21.3 \%)$ \\
\hline Disorder (G) & $10(5.6 \%)$ & $17(11.3 \%)$ & $27(8.2 \%)$ \\
\hline Panic Disorder (P) & $5(2.8 \%)$ & $12(7.9 \%)$ & $17(5.2 \%)$ \\
\hline Substance use Disorder (SU) & $68(38.2 \%)$ & $18(11.9 \%)$ & $86(26.1 \%)$ \\
\hline No psychiatric Disorder & $75(42.1 \%)$ & $54(35.8 \%)$ & $129(39.2 \%)$ \\
\hline
\end{tabular}

$\mathrm{X}^{2}=48.15 ; \mathrm{df}=6 ; \mathrm{p}=0.000$

Table 4: Association between psychiatric morbidity and category of violent offenders

\section{Relationship between Sociodemographic characteristics and psychiatric morbidity of violent offenders}

Age was the only Sociodemographic variable found to be statistically significant with psychiatric morbidity among violent offenders in the study $(\mathrm{p}=0.040)$ (Table 5)

Table 5 showed a significant relationship between age group and psychiatric morbidity of violent offenders. It highlighted that majority $66.5 \%$ of the younger $25-34$ years violent offenders had psychiatric morbidity.

\begin{tabular}{|c|c|c|c|}
\hline \multicolumn{3}{|c|}{ N=329 } \\
\hline Variables & Psychiatric disorder & No psychiatric disorder & Total \\
\hline Age in years & & & $52(100 \%)$ \\
\hline $15-24$ & $28(53.8 \%)$ & $24(46.2 \%)$ & $158(100 \%)$ \\
\hline $25-34$ & $105(66.5 \%)$ & $53(33.5 \%)$ & $81(100 \%)$ \\
\hline $35-44$ & $41(50.6 \%)$ & $40(49.4 \%)$ & $18(100 \%)$ \\
\hline $45-54$ & $10(55.6 \%)$ & $8(44.4 \%)$ & $20(100 \%)$ \\
\hline$>55$ & $16(80.0 \%)$ & $4(20.0 \%)$ & \\
\hline
\end{tabular}

$\mathrm{X}^{2}=10.00 ; \mathrm{df}=5 ; \mathrm{p}=0.040$

Table 5: Relationship between age and psychiatric morbidity among violent offenders 


\section{Discussion}

The majority of the participants studied were young males, single, with low educational achievement. The age bracket 15 -34 years constituted more than half of those studied. This conform to the study of offence related characteristics of homicide offenders in Nigeria where almost all (95.5\%) the studied subjects were males, with most $(78.8 \%)$ of the subjects less than 40 years of age [32]. A study in United Kingdom found majority of convicted armed robbers to be males with less than $1 \%$ female armed robbers (Morrison \& Donnell, 1994). Another study by Borzycki (2006) reported that most convicted armed robbers are less than 30 years of age. A similar result was also reported from a study of homicide offenders in Jimma prison, Ethiopia were authors found more than half of their male studied subjects to be within the age bracket of 20-39 years (Audu et al, 2008). This may be explained by the fact that younger people tend to be more aggressive due to multiplicity of factors such as lots of energy, unemployment, isolation, generation gap (generation conflict), poor supervision, adventurous and peer pressure [31]. Furthermore, youths try to identify with members of their subculture and exercise certain choices in the context of affiliation and significance.

Significant relationship was found between age of the participants and psychiatric morbidity $(\mathrm{P}=0.040)$ and substance use disorder was the commonest disorder; which is more glaring between the young and youthful age brackets 15 - 34 years where 4 in 10 of the participants had a psychiatric diagnosis. The young age group was significantly more prone to developing mental illness possibly due to considerably ingestion of psychoactive substances due to various psychosocial stresses at that age bracket.

Almost half of the studied participants (46.2\%) had some form of secondary school education and about 4 in 10 of these participants were unemployed at the time of committing crime. This finding is in contrast to an Australian study were few convicted violent offenders completed high school education, but similar in the sense that few were engaged in skilled employment [33]. A similar result was found by Kapardis (1988) in an Australian study where author reported most convicted violent offenders (armed robbers) to possess no employment skills and a third have worked as labourers earlier in life. A study on homicide offenders in Nigeria by Fatoye et al (2010) [32] found a similar result where unemployment was reported in (45.5\%) of their subjects. It should be understood that crime is not synonymous with poor educational status or low socioeconomic class. Cases of bank frauds and corruption among top ranking government officials are common occurrences nowadays in the society (citied by Agboola 2006). The educated and rich could bribe their way out of prosecution or hire highly qualified lawyers to defend them (Agomoh, 1993).

Half $(50.2 \%)$ of the studied participants were single, with a third of them married. A Nigerian study found similar result, authors found more than half of their studied subjects $(53.0 \%)$ to be single, while (39.4\%) were married [32]. It is widely believed that marriage confers some measure of responsibility on an individual, and reduces the tendency to commit crime because of the fear of societal response to the act.

Psychiatric morbidity was found in more than half (60.8\%) of the participants in this study. The finding is in concordance with the study on convicted homicide /attempted homicide offenders in Turkey where authors found psychiatric morbidity in (51.4\%) of their studied sample [19]. The finding of the present study is in contrast to a Nigerian study on homicide offenders where psychiatric morbidity was lower (43.2\%) among the offenders [20]. There was a preponderance of Substance Use Disorders (43\%). This is in consonance with the findings of other studies which have generally found more substance use disorders, such as the studies of Audu et al (2008) who studied life time prevalence of substance use disorder and mental distress among homicide offenders in Jimma prison Ethiopia they found higher rate (64.1\%) of inmates abused substances and [19] reported similar findings to present study $(45.7 \%)$.

A statistical significant relationship was found between psychiatric morbidity and category of violent offenders $(p=0.000)$. More violent offenders awaiting trial had diagnosis of substance use disorder. Several studies have reported that either alone or in combination with psychiatric disorder the use of substances elevates the risk of violence which ultimately leads to crime [17,34]. A study by MacArthur Violence risk assessment team reported that the risk of violence is doubled in individuals that use substances concurrently $[35,36]$

\section{Conclusion}

The above study found a high prevalence of psychiatric morbidity, with substance use disorder (SUD) the commonest among violent offenders. The study revealed a significant association between psychiatric morbidity specifically SUD, with the young and youthful age bracket of 15-34 years. They is the need for urgent attention in the prison with the aim of reducing the burden of psychiatric disorders particularly substance use disorder and addressing the possible stressors. Researchers suggest the need for more research in this area with the aim of considering the formulation of policies favourable to the violent mentally ill offenders such as rehabilitative measure to help assist these offenders.

\section{Recommendation}

There is need to enhance public awareness on the harmful effects of psychoactive substance abuse and intensify efforts on the primary prevention of mental disorders especially at the grassroots level.

\section{Limitation}

The study is cross-sectional and involved only one maximum security prison as such generalizing from a single study might not be apt. 


\section{References}

1. The World Health Organization (2002) World report on violence and health, Geneva.

2. Centre for Disease control and prevention (2006) Homicides and suicides- National violent death reporting system, United States, 2003-2004. MMWR Morb Mortal WKLY Rep 55: 721-4.

3. Lopez AD, Mathers CD, Ezzati M, Jamison DT, Murray CJ (2006) Global and regional burden of disease and risk factors, 2001: systematic analysis of population health data. Lancet 367: 1747-57.

4. Jacoby T (2008) Understanding conflict and violence: Theoretical and interdisciplinary approaches. Routledge, London.

5. Rueve ME, Welton RS (2008) Violence and mental illness. Psychiatry (Edgmont) 5: 34-48.

6. Stamp F (2014) Psychiatric treatment of violent offenders in prison. Serious Violent Offenders: Sentencing, Psychiatric and Law Reform.

7. Mackintosh J (1990) Theories of aggression in principles and practice of forensic psychiatry. Churchill Livingston, New York.

8. Mullen PE (1997) A reassessment of the link between mental disorder and violent behaviour, and its implications for clinical practice. Aust N Zeal J Psychiatry 31:3-11

9. Marzuk PM (1996) Violence, crime and mental illness. How strong a link? Arch Gen Psychiatry 53: 481-6.

10. Wessely S (1993) Violence and psychosis. Basic and Clinical Science. Oxford: Butter-worth/Heinemann 119-34.

11. Link BG, Stueve A (1995) Evidence bearing on mental illness as a possible cause of violent behaviour. Epidemiol Rev 17: 172-81.

12. Noffsinger SG, Resnick PJ (1999) Violence and mental illness. Curr Opin Psychiatry 12: 683-7.

13. Mulvey EP (1994) Assessing the evidence of a link between mental illness and violence. Hosp Community Psychiatry 45: 663-8.

14. Holcomb WR, Ahr PR (1988) Arrest rates among young psychiatric patients treated in inpatient and outpatient settings. Hosp Community Psychiatry 39: 52-7.

15. Eronen M, Hakola P, Tihonen J (1996) Mental disorders and homicidal behaviour in Finland. Arch Gen Psychiatry 53: 497-501.

16. Steadman HJ, Mulvey EP, Monahan J, Robbins PC, Appelbaum PS, et al (1998) Violence by people discharged from acute psychiatric inpatient facilities and by others in the same neighbourhoods. Arch Gen Psychiatry 55: 393-401.

17. Wallace C, Mullen PE, Burgess P (2004) Criminal offending in schizophrenia over a 25 year period marked by deinstitutionalization and increasing prevalence of comorbid substance use disorder. Am J Psychiatry 161: 716-27.

18. Fazel S, Grann M (2004) Psychiatric morbidity among homicide offenders: a Swedish population study. Am J Psychiatry 161: 2129-31.

19. Kugu N, Akyuz G, Dogan O (2007) Psychiatric morbidity in murder and attempted murder crime convicts: A Turkey study. Foren sci int 175: 107-12.

20. Mafullul YM (1997) A psycho-social study of convicted homicide offenders in a Northern Nigerian prison. Unpublished fellowship thesis submitted to the West Africa College of Physicians.

21. Mafullul YM, Ogunlesi AO, Sijuwola OA (2001) Psychiatric aspect of criminal homicide in Nigeria. A review. East African J Med 78: 35-9.

22. Armiyảu AY, Audu MD, Obembe A (2014) Depression, anxiety and substance use disorder among awaiting trial inmates in Jos maximum security prison. J Ment Health Care 1: 67-81.

23. Goldberg DP, Hillier VF (1979) 28-item general health questionnaire (GHQ-28). Psychol Med 9: 139-45.

24. Goldberg DP, William PA (1988) Users guide to the General Health Questionnaire. London: NFER-Nelson.

25. Goldberg DP (1972) The detection of psychiatric illness by questionnaire. A Monograph (21) Oxford University Press London.

26. Omigbodun OO (1991) Screening children for psychiatric morbidity in primary health care. A dissertation submitted to West Africa College of Physicians.

27. Aderibigbe YA, Gureje O (1992) The validity of the 28-item general health questionnaire in a Nigerian antenatal clinic. Soc Psychiatry Psychiatr Epidemiol 27: 280-3.

28. Singleton N, Gatward R (1998) Psychiatric morbidity among prisoners in England and Wales (office for national statistics). London Stationary Office.

29. World Health Organization (1992-1993) International Classification of Mental and Behavioural Disorder (ICD 10). WHO Geneva.

30. Gureje O, Lasebikan VO, Lola K, Makanjuola VA (2006) Lifetime and 12 month prevalence of mental disorders in the Nigerian Survey of Mental health and wellbeing. British J Psych 188: 465-71.

31. Armiya'u AY, Obembe A, Audu MD, Afolaranmi TO (2013) Prevalence of psychiatric morbidity among inmates in Jos maximum security prison. Open Journal of Psychiatry 3: 12-7.

32. Fatoye FO, Eegunranti BA, Fatoye GK, Amoo G, Omoaregba JO, et al. (2010) Sociodemographic and offence related characteristics of homicide offenders in a Nigerian prison. Nig J Psychiatry 8: 21-5.

33. Nugent S, Burns D, Wilson P, Chappell D (1989) Armed robbery from an offender's perspective: implications for prevention. Canberra AIC.

34. Swanson JW, Holzer CE, Gangu VK, Jono RT (1990) Violence and psychiatric disorder in the community: evidence from the epidemiological catchment area surveys. Hosp Community Psychiatry 41: 761-70.

35. Appelbaum PS, Robbins PC, Monahan J (2000) Violence and delusions: data from the MacArthur Violence Risk Assessment Study. Am J Psychiatry 157: 566-72. 36. Sirotich F (2008) Correlated of crime and violence among persons with mental disorder: An Evidence based review. Brief Treat Crisis Interv 8: $171-94$. 


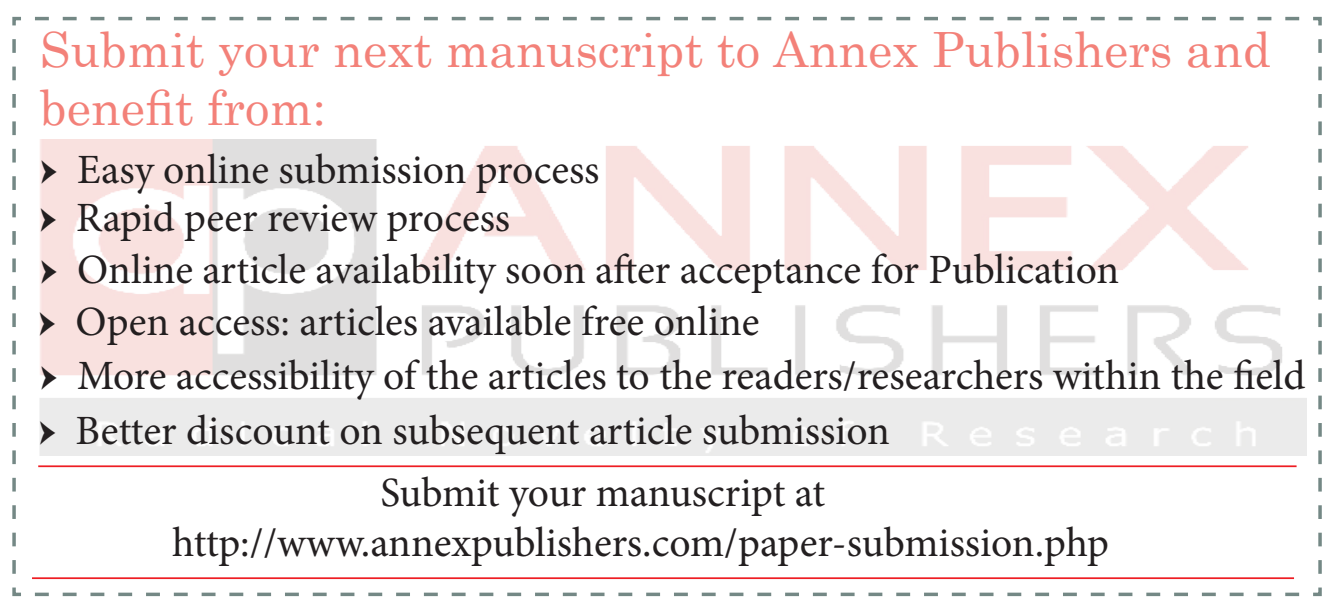

